\title{
HIV/AIDS ASSOCIATED ISOSPORA BELLI INFECTION IN KUMAUN REGION, UTTARAKHAND
}

\author{
Archana Mohan'1, Umesh², Mukesh Kumar ${ }^{3}$, Ashok Kumar ${ }^{4}$ \\ 1 Junior Resident, Department of Microbiology, Government Medical College, Haldwani. \\ 2Professor and HOD, Department of Microbiology, Government Medical College, Haldwani. \\ ${ }^{3}$ Assistant Professor, Department of Microbiology, Government Medical College, Haldwani. \\ ${ }^{4}$ Associate Professor, Department of Medicine, Government Medical College, Haldwani.
}

ABSTRACT

\section{BACKGROUND}

Human immunodeficiency virus (HIV) seropositive patients usually suffer from opportunistic intestinal parasitic infections leading to high mortality and morbidity. Knowledge about the aetiological agents in HIV can often guide the treatment.

The objective of this study was to determine the prevalence of Isospora belli infections in HIV-positive patients with diarrhoea attending Dr. Susheela Tiwari Government Hospital, Haldwani and its correlation with CD4 + T lymphocytes counts.

\section{MATERIALS AND METHODS}

All the HIV-positive patients of both the sexes and all age groups presenting with diarrhoea to ART Centre, Dr. Susheela Tiwari Government Hospital, Haldwani were included in the study. A total of 104 patients were enrolled during the study period by consecutive sampling method. The samples were processed using saline, iodine mount and modified Ziehl-Neelsen staining technique to identify the presence of Isospora belli oocysts.

\section{RESULTS}

The prevalence of Isospora belli infection in the study was $16.3 \%$. It was observed to be higher among patients with CD4+ T cell counts $\leq 200$ cells $/ \mu \mathrm{L}$ in patients with chronic diarrhoea and in patients not taking Anti-retroviral therapy.

\section{CONCLUSION}

It is recommended that stool samples of HIV seropositive patients should be examined routinely for opportunistic intestinal parasites like Isospora belli in order to institute appropriate treatment.

\section{KEYWORDS}

HIV/AIDS, Isospora Belli Infection.

HOW TO CITE THIS ARTICLE: Mohan A, Umesh, Kumar M, et al. HIV/AIDS associated isospora belli infection in Kumaun region, Uttarakhand. J. Evolution Med. Dent. Sci. 2017;6(52):3959-3962, DOI: 10.14260/Jemds/2017/857

\section{BACKGROUND}

Acquired Immunodeficiency Syndrome (AIDS) is the major global public health problem of the $21^{\text {st }}$ century. The growing number of people living with HIV has constantly been detected in the world over and in particular from the three main continents, Asia, South America and sub-Saharan Africa. ${ }^{1}$ Opportunistic infections (OIs) are one of the existing identified causes that aggravate the condition of HIV infected patients. Of these, parasites play an important role as OIs and are one of the most common causes of morbidity and mortality in HIV/AIDS patients. ${ }^{2}$ Patients are predisposed to severe and prolonged diarrhoea caused by opportunistic parasites, particularly Isospora belli, which is one of the most commonly identified causes of diarrhoea in AIDS patients. ${ }^{3}$

The objective of this study was to determine the prevalence of Isospora belli infections and their correlation to CD4+ $\mathrm{T}$ cell counts among HIV-positive patients with diarrhoea.

Financial or Other, Competing Interest: None.

Submission 24-05-2017, Peer Review 17-06-2017,

Acceptance 23-06-2017, Published 29-06-2017.

Corresponding Author:

Dr. Umesh,

Professor and $H O D$

Department of Microbiology,

Government Medical College,

Rampur Road, Haldwani (Nainital), Uttarakhand.

E-mail:drumesh7@rediffmail.com

DOI: $10.14260 /$ jemds $/ 2017 / 857$

\section{MATERIALS AND METHODS}

This descriptive cross-sectional study was conducted at Dr. Susheela Tiwari Government Hospital, Haldwani, between October 2014 and June 2016. The hospital is a tertiary care centre offering services to a large population from Kumaun and nearby areas.

All the HIV-positive patients of both the sexes and all age groups presenting with diarrhoea (Three or more loose or liquid stools per day) to ART centre, Dr. Susheela Tiwari Government Hospital, Haldwani were enrolled in the study. Those who have taken antiparasitic treatment in the past 14 days were excluded. A total of 104 patients were enrolled during the study period by consecutive sampling method.

The study included 56 males and 48 females. Informed written consent was taken from each subject prior to specimen collection, and samples were taken only from those who indicated their willingness to participate in the study.

Stool examination was done as per the standard guidelines. Patients were given labelled, leak proof, clean sterile plastic containers to collect stool samples. The consistency (Liquid, semisolid or formed) of stool samples, colour, presence of blood and mucus, visible worms and $\mathrm{pH}$ was noted. A direct wet mount of stool in normal saline $(0.85 \%)$ and Lugol's iodine was prepared and examined under light microscope. The modified acid-fast staining technique (Kinyoun's method) was used for Isospora after concentration by the formol-ether sedimentation technique. 4

The concentration procedure recommended is the Formol-ether (Formalin-ethyl acetate) method. According to 
WHO 20044 , using a wooden applicator stick, 1.0 to $1.5 \mathrm{~g}$ faeces was added to $10 \mathrm{~mL}$ of $10 \%$ formalin in a centrifuge tube, stirred and thoroughly emulsified and brought into suspension. Next, the suspension was strained through the $400 \mu \mathrm{m}$ mesh sieve or 2 layers of wet surgical gauze directly into a different $15 \mathrm{~mL}$ centrifuge tube or into a small beaker. The gauze was then discarded and more $10 \%$ formalin was added to the suspension in the tube to bring the total volume to $10 \mathrm{~mL}$. Then, $3.0 \mathrm{~mL}$ of formalin-ether (or ethyl-acetate or gasoline) was added to the suspension in the tube, and mixed well by putting a rubber stopper in the tube and shaken vigorously for 10 seconds. The content was centrifuged at 400-500 x g for 2-3 minutes or at $2000 \mathrm{rpm}$ for 10 minutes. The supernatant [comprising the top 3 layers (a) top layer of formalin-ether (or ethyl-acetate or gasoline); (b) a plug of fatty debris that is adherent to the wall of the tube; (c) a layer of formalin] was decanted leaving behind the deposit/sediment. A few drops of the suspension were transferred onto a microscope slide and covered with a cover slip; an iodine-stained preparation can also be made. Finally, the preparations were examined microscopically using the low power (X 10) objective and in a systematic manner as to observe the entire coverslip area. Whenever an organism or suspicious objects were seen, the higher magnification (X 40 objective) was used (Figure 1).

\section{Modified Ziehl-Neelsen Method (Acid-Fast Stain) according to WHO 2004[4]}

Carbol-fuchsin, formalin, HCl-ethanol solution, glycerol malachite green (or methylene blue) solution, $\mathrm{HCl}$-methanol solution. (Hi-media laboratories, Mumbai India) were reagents used.

\section{Staining Procedure}

A thin smear was prepared directly from fresh as well as from sediments of concentrated stool and allowed to air dry. Then the slides were fixed with methanol for 2-3 minutes and stained with cold carbol-fuchsin for 5-10 min.; then washed with tap water and decolourised with acid alcohol $(1 \mathrm{~mL} \mathrm{HCl}$ and $99 \mathrm{~mL}$ of $96 \%$ ethanol) until colour ceases to flow out of smear. After washing the slides with tap water, it was counterstained with $0.25 \%$ malachite green (or methylene blue) for 30 seconds to 1 minute. Finally, the slides were washed in tap water and allowed to air dry. The slides were then observed under light microscope with X100 magnification (Figure 2).

The CD4+ T-cell count estimation was done using the CyFlow counter, Partec, Germany. Most recent value of $\mathrm{CD} 4+\mathrm{T}$ cell count was taken for analysis.

The study was approved by the Institutional Ethical Committee of Dr. Susheela Tiwari Government Hospital, Haldwani after due permission from NACO/USACS.

Statistical analysis was done using SPSS version 18.0 software. Chi- square $(\chi 2)$ test, Fisher exact test and odds ratio analysis was done. P-value $\leq 0.05$ was considered statistically significant.

\section{RESULTS}

During the study period, 104 HIV-positive patients with diarrhoea were examined for Isosporiasis. Among these patients, 48 were female and 56 were male patients. An overall prevalence rate of $16.3 \%$ was observed in this study, with $12(21.4 \%)$ males and $5(10.4 \%)$ females infected with Isospora belli. (Table 1).

\begin{tabular}{|c|c|c|c|c|}
\hline Gender & $\begin{array}{c}\text { Infection } \\
\text { Present (\%) }\end{array}$ & $\begin{array}{c}\text { Infection } \\
\text { Absent (\%) }\end{array}$ & Total & $\begin{array}{c}\mathbf{P}^{*} \\
\text { value }\end{array}$ \\
\hline Female & $5(10.4 \%)$ & $43(89.6 \%)$ & 48 & \multirow{3}{*}{0.130} \\
\hline Male & $12(21.4 \%)$ & $44(78.6 \%)$ & 56 & \\
\hline Total & 17(16.3\%) & $87(83.6 \%)$ & 104 & \\
\hline
\end{tabular}

${ }^{*}$ Chi sq value is $2.292, \mathrm{df}=1$ although greater percentage of males i.e. $21.4 \%$ were infected than females $(10.4 \%)$ but the difference was non-significant statistically.

The results showed that the highest prevalence of $23.5 \%$ was found in the 41-60 years age group but this difference was not significant statistically. (Table 2).

\begin{tabular}{|c|c|c|c|c|}
\hline $\begin{array}{c}\text { Age- } \\
\text { Groups }\end{array}$ & $\begin{array}{c}\text { Total } \\
\text { Patients } \\
(\mathbf{M}+\mathrm{F})\end{array}$ & $\begin{array}{c}\text { Infection } \\
\text { Present } \\
(\%)\end{array}$ & $\begin{array}{c}\text { Infection } \\
\text { Absent } \\
(\%)\end{array}$ & $\begin{array}{c}\text { P\# value } \\
\text { (Using } \\
\text { Fisher's } \\
\text { Exact Test) }\end{array}$ \\
\hline $0-20$ & 11 & 0 & 11(100) & \multirow{4}{*}{0.229} \\
\hline $21-40$ & 76 & $13(17.1)$ & $63(82.8)$ & \\
\hline $41-60$ & 17 & $4(23.5)$ & $13(76.4)$ & \\
\hline Total & 104 & $17(16.3)$ & $87(83.6)$ & \\
\hline
\end{tabular}

Higher prevalence of isosporiasis was seen in patients with CD4 $\leq 200$ cells/ $\mu \mathrm{L}$ as compared to those with higher CD4 + T cell counts. (Table 3 ).

\begin{tabular}{|c|c|c|c|c|c|}
\hline $\begin{array}{c}\text { CD4 + } \\
(\text { cells } / \mu \mathrm{L})\end{array}$ & $\begin{array}{c}\text { Infection } \\
\text { Present } \\
(\%)\end{array}$ & $\begin{array}{c}\text { Infection } \\
\text { Absent } \\
(\%)\end{array}$ & Total & $\begin{array}{c}\text { Odds } \\
\text { Ratio } \\
95 \% \text { CI }\end{array}$ & $\begin{array}{c}\mathbf{P}^{*} \\
\text { value }\end{array}$ \\
\hline$\leq 200$ & $\begin{array}{c}13 \\
(44.8 \%)\end{array}$ & $\begin{array}{c}16 \\
(55.2 \%)\end{array}$ & 29 & \multirow{3}{*}{$\begin{array}{c}14.42 \\
(50.08 \\
\text { to } 4.15)\end{array}$} & \multirow{3}{*}{0.001} \\
\hline$>200$ & $\begin{array}{c}4 \\
(5.3 \%) \\
\end{array}$ & $\begin{array}{c}71 \\
(94.7 \%) \\
\end{array}$ & 75 & & \\
\hline Total & $\begin{array}{c}17 \\
(16.3 \%) \\
\end{array}$ & $\begin{array}{c}87 \\
(83.6 \%)\end{array}$ & 104 & & \\
\hline Table & $\begin{array}{l}\text { Isosporia } \\
\text { Associatic }\end{array}$ & with $C D$ & $\pi$ & unts & \\
\hline
\end{tabular}

*Fisher exact test as 1 cell expected count is $<5, \mathrm{df}=1$. The proportion of Isospora infected cases is more in patients with CD 4 count $\leq 200(44.8 \%)$ than in CD4 count $>200$ (5.3\%) and this difference is found to be significant statistically. Also, the odds ratio of the presence of Isospora belli infection with CD4 count $\leq 200$ versus $>200$ is 14.42 which is greater than 1 and thus showing positive association of lesser number of CD4 count with Isospora belli infection presence in HIV/AIDS patients

The prevalence of Isospora belli infection in patients with chronic diarrhoea was greater $(19.6 \%)$ than in patients with acute diarrhoea $(11.6 \%)$ but this difference was not found to be significant statistically $(\mathrm{p}=0.27)$ (Table 4$)$. 


\begin{tabular}{|c|c|c|c|c|c|}
\hline \multirow{2}{*}{ Diarrhoea } & Isospora Infection & \multirow{2}{*}{$\begin{array}{c}\text { Total } \\
(\mathbf{\%})\end{array}$} & $\begin{array}{c}\text { Chi sq } \\
\text { value } \\
\left(\mathbf{X}^{2}\right)\end{array}$ & $\begin{array}{c}\text { P } \\
\text { value }\end{array}$ \\
\cline { 2 - 5 } & + & - & $61(58.6)$ & & \\
\hline Chronic & $12(19.6 \%)$ & $49(80.3 \%)$ & & 0.27 \\
\hline Acute & $5(11.6 \%)$ & $38(88.3 \%)$ & $43(41.3)$ & 1.19 & 0.27 \\
\hline & $\begin{array}{c}\mathbf{1 7} \\
(\mathbf{1 6 . 3 \% )})\end{array}$ & $\mathbf{8 7}(\mathbf{8 3 . 6 \% )}$ & $\begin{array}{c}\mathbf{1 0 4} \\
(\mathbf{1 0 0 )}\end{array}$ & & \\
\hline Table 4. Isosporiasis in Patients with Acute and Chronic \\
Diarrhoea \\
\hline
\end{tabular}

The percentage of Isospora belli infection in patients without ART was greater $(29.4 \%)$ than in patients with ART $(10 \%)$ and this difference was found to be significant statistically $(p=0.012)$ (Table 5).

\begin{tabular}{|c|c|c|c|c|}
\hline $\begin{array}{c}\text { Patient } \\
\text { Status }\end{array}$ & $\begin{array}{c}\text { Infection } \\
\text { Present (\%) }\end{array}$ & $\begin{array}{c}\text { Infection } \\
\text { Absent (\%) }\end{array}$ & Total & $\begin{array}{c}\text { P } \\
\text { value }\end{array}$ \\
\hline $\begin{array}{c}\text { Patients with } \\
\text { ART }\end{array}$ & $7(10 \%)$ & $63(90 \%)$ & $70(100 \%)$ & \multirow{2}{*}{0.012} \\
\cline { 1 - 3 } & $10(29.4 \%)$ & $24(70.6 \%)$ & $34(100 \%)$ & \\
without ART & Pathon &
\end{tabular}

\section{Table 5. Distribution of Isospora belli among HIV positive}

Patients with and without Antiretroviral Therapy (ART)

${ }^{*}$ Chi sq value is $6.306, \mathrm{df}=1$.

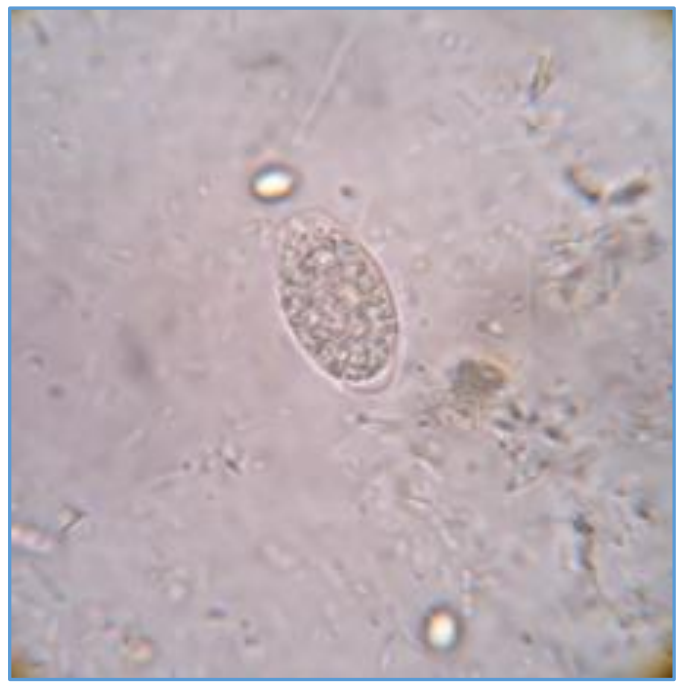

Figure 1. Showing Oocyst of Isospora belli Figure (Saline Mount)

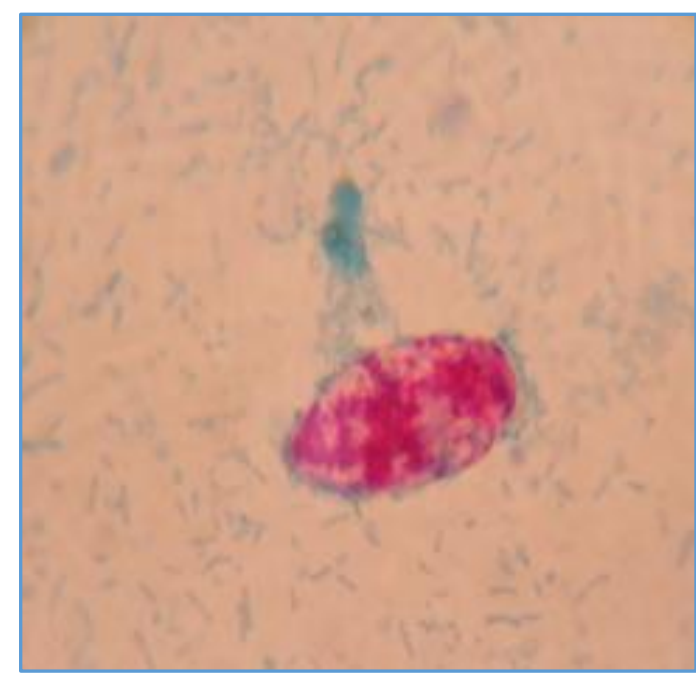

Figure 2. Showing Oocyst of Isospora belli (Modified Z-N Staining)

\section{DISCUSSION}

Isospora belli is a protozoan parasite of the phylum Apicomplexa, class Sporozoa, subclass Coccidian and family Eimeriidae. The parasite invades the small intestine epithelium and completes its life cycle in the cytoplasm of the enterocyte. Oocysts excreted in faeces develop into mature cysts outside the host; each oocyst containing two sporoblasts, which in turn contain four sporozoites. The sporulated oocysts are the infective stage, which upon ingestion exist in the small intestine. Intestinal infection due to I. belli is distributed worldwide, however, higher incidence is reported from developing regions of the world. ${ }^{5}$

To our knowledge, this is the first study to be carried out on the prevalence of Isospora belli infection in HIV-positive patients in Kumaun region. The results obtained in this study can provide important information for future understanding of isosporiasis in HIV-positive patients.

An overall prevalence rate of Isosporiasis observed in this study was $16.3 \%$. The findings were comparable with a study by Mehta et al with $18 \%$ prevalence. ${ }^{6}$ A study by Sarfati et al reported the prevalence of $6.5 \%$ which was lower than observed in the present study. ${ }^{7}$ Tuli et al reported lower prevalence of $0.5 \% .^{8}$ Study by Vignesh et al reported a higher prevalence of $26.1 \%{ }^{3}$

The prevalence was observed to be higher in males 21.4 $\%(12 / 56)$ as compared to females $10.4 \%(5 / 48)$ (Table 1$)$. The results showed that the highest prevalence was found in the 41-60 years age group which was similar to the finding observed by Akinbo et al. 9 The association between Isosporiasis and age group was not found to be significant statistically ( $\mathrm{P}>0.05)$. (Table 2$)$.

Higher number of parasites were isolated from patients with CD4+T cells count $\leq 200$ cells $/ \mu \mathrm{L} \quad(\mathrm{OR}=14.42,95 \%$ $\mathrm{CI}=50.08-4.15, \mathrm{P}=0.001)$. The findings were in accordance with study conducted by Akinbo et al. ${ }^{9}$ The presence of opportunistic parasites was inversely proportional to the CD4+ T-cell counts in these patients, i.e. the lower the CD4 counts the more were the chances of isolation of parasites. This higher Isospora belli infection rate may be the result of the low immune status of these patients, which exposes them to opportunistic infections. The effects of isosporiasis may lead to increase in morbidity and mortality in these patients.

The prevalence of Isospora belli infection in patients with chronic diarrhoea was greater $(19.6 \%)$ than in patients with acute diarrhoea (11.6\%) but the difference was not found to be significant statistically $\left({ }^{*} \mathrm{Chi}\right.$ sq value $=1.19, \mathrm{P}=0.27$ ).

The percentage of Isospora belli infection in patients without ART is greater $(29.4 \%)$ than in patients with ART $(10 \%)$ and this difference is found to be significant statistically ( ${ }^{*} \mathrm{Chi}$ sq value is $6.306, \mathrm{df}=1, \mathrm{P}=0.012$ ). In spite of the treatment with Anti-retroviral therapy (including trimethoprim-sulfamethoxazole), the patients were suffering from isosporiasis $(10 \%)$. This may be due to under dosage, non-compliance, relapses after discontinuation or emergence of drug resistance.

The patients were treated with Trimethoprim $(160 \mathrm{mg}$ ) and Sulfamethoxazole $(800 \mathrm{mg})$ thrice daily for 10 days. Maintenance therapy with TMP-SMX (160 mg/800 mg) per oral 3 times weekly till CD4 count $>200$ cells $/ \mu \mathrm{L}$ for $>6$ months was reached. 


\section{CONCLUSION}

This study has demonstrated that Isospora belli infection is prevalent in Kumaun region, Uttarakhand and, as a result, may increase the burden on HIV-positive patients. I. belli should be considered a part of spectrum of potentially treatable infectious agents in patients with AIDS. The high prevalence of Isosporiasis in HIV-positive patients warrants urgent need of intervention so as to avoid its consequences. Screening for these infections is therefore essential for early diagnosis and treatment. As the transmission is faeco-oral, improvement of sanitation, proper drinking water and health education may help in decreasing the prevalence.

\section{ACKNOWLEDGEMENTS}

We acknowledge NACO/USACS and the Institutional Ethical Committee for granting permission to carry out the present study. We are also grateful to the HIV/AIDS patients who participated in this study.

\section{REFERENCES}

[1] UNAIDS. Report on the global AIDS epidemic. Epidemic update, 2010.

[2] CDC. Revision of the CDC surveillance case definition for acquired immunodeficiency syndrome. Council of State and Territorial Epidemiologists: AIDS Program, Center for Infectious Diseases. MMWR Suppl 1987;36(1):1S-15S.
[3] Vignesh R, Balakrishnan P, Shankar EM, et al. Short report: High proportion of Isosporiasis among HIVinfected patients with diarrhea in Southern India. Am J Trop Med Hyg 2007;77(5):823-4.

[4] World Health Organization, Geneva. Training manual on diagnosis of intestinal parasites. 2004:1-43.

[5] Stark D, Barratt JL, van Hal S, et al. Clinical significance of enteric protozoa in the immunosuppressed human population. Clin Microbiol Rev 2009;22(4):634-50.

[6] Mehta KD, Vacchani A, Mistry MM, et al. To study the prevalence of various enteric parasitic infections among HIV infected individuals in in the P.D.U. Medical College and Hospital, Rajkot, Gujarat, India. JCDR 2013;7(1):5860.

[7] Sarfati C, Bourgeois A, Menotti J, et al. Prevalence of intestinal parasites including Microsporidia in a HIV infected adults in Cameroon: a cross-sectional study. Am J Trop Med Hyg 2006;74(1):162-4.

[8] Tuli L, Gulati AK, Sundar S, et al. Correlation between CD4 counts of HIV patients and enteric protozoan in different seasons - an experience of a tertiary care hospital in Varanasi (India). BMC Gastroenterol 2008;8:36.

[9] Olusegun AF, Okaka CE, Machado RLD. Isosporiasis in HIV/AIDS patients in Edo state, Nigeria. Malaysian Journal of Medical Sciences 2009;16(3):43-4. 